\title{
Controle químico da mancha-bacteriana do tomate para processamento industrial em campo
}

\author{
Abadia dos R Nascimento ${ }^{1}$; Paulo M Fernandes ${ }^{1}$; Lino Carlos Borges ${ }^{1}$; Antonio W Moita²; Alice Maria \\ Quezado-Duval' \\ 'UFG-Esc. de Agronomia, 74001-970 Goiânia-GO; ²Embrapa Hortaliças, C. Postal 218, 70351-970 Brasília-DF; alice.quezado@em- \\ brapa.br
}

\section{RESUMO}

Com o objetivo de avaliar produtos químicos no controle da mancha-bacteriana em tomate para processamento industrial, foram conduzidos dois ensaios na área experimental da Unilever Bestfoods, em Goiânia-GO. No primeiro, o híbrido Heinz 9992 foi inoculado com Xanthomonas perforans em blocos casualizados, com 15 tratamentos e três repetições. O segundo ensaio foi em blocos ao acaso com parcelas subdivididas com três repetições. A parcela principal foi "tratamento químico" (10 tratamentos) e a subparcela "híbrido" (Hypeel 108 e U2006). Inoculou-se X. perforans e X. gardneri. Em ambos os ensaios os produtos testados, em diferentes números de aplicações e regimes, foram: acibenzolar-S-metil (ASM); famoxadona + mancozebe; metiram + piraclostrobina; fosfito PK; cloretos de benzalcônio; óxido cuproso e hidróxido de cobre (SC, WP e WG). Em ambos os ensaios, foram avaliados severidade da doença nas folhas, número de frutos com sintomas e produtividade. No segundo ensaio avaliou-se também o número de frutos com escaldadura. No primeiro ensaio foram detectadas diferenças significativas $(p>0,05)$ entre os tratamentos somente nas duas primeiras avaliações de severidade, mas nenhum dos tratamentos diferiu da testemunha. No segundo ensaio, para severidade foliar, foi detectada diferença significativa apenas para os híbridos na primeira avaliação. Para número de frutos com sintomas e escaldadura a interação entre os fatores "tratamento químico" e "híbrido" foi também significativa. Nas folhas, 'U2006' foi mais resistente do que 'Hypeel 108', que apresentou maior incidência de escaldadura, mas nos frutos ocorreu o inverso. Para produtividade, os dois fatores foram significativos. 'U2006' foi mais produtivo do que 'Hypeel 108'. Entre os 10 tratamentos químicos, apesar de nenhum ter diferido da testemunha, famoxadona + mancozebe, que resultou em maior produtividade, diferiu de hidróxido de cobre (WG), ASM - famoxadona + mancozebe e cloretos de benzalcônio. ASM e famoxadona + mancozebe foram os que promoveram uma relação benefício/custo superior a 1 .

Palavras-chave: Solanum lycopersicum, Xanthomonas perforans, Xanthomonas gardneri, agrotóxicos, indutor de resistência.

\begin{abstract}
Field chemical control of bacterial spot on tomato for industrial processing

In order to evaluate chemical control of bacterial spot on tomato for industrial processing, two field trials were carried out at the Unilever Bestfoods experimental station, in Goiânia, Goias state, Brazil. The first trial was in a randomized complete block design, with 15 treatments and three replications, using the hybrid Heinz 9992 inoculated with Xanthomonas perforans. The second trial was in a split-plot randomized complete block design with chemical foliar applications (10 treatments) and hybrids (Hypeel 108 and U2006) as factors. Plants were inoculated with $X$. perforans and $X$. gardneri. In both trials the chemicals, in different number of applications and combinations, were: acibenzolar-S-methyl (ASM); famoxadone + mancozeb; metiram + pyraclostrobin; phosphite PK; benzalkonium chlorides; cuprous oxide, and copper hydroxide (SC, WP and WG). For both trials, disease severity on leaves, number of fruits with symptoms and yield were evaluated. In the second one, sunscald was also evaluated. For the first trial, significant severity differences ( $p>0.05)$ among treatments were observed only in the first two evaluations, but none of them differed from the water check control. In the second trial, significant differences were detected only in foliar severity in first evaluation for hybrids. For number of fruits with symptoms and sunscald, besides hybrids, interaction among factors was also significant. 'U2006' was more resistant than 'Hypeel 108', which also had highest sunscald values, but concerning fruits with symptoms, the opposite was observed. The two factors were significant for yield data, 'U2006' yielded better than 'Hypeel 108'. Despite none of the treatments have differed in yield from the water control, famoxadone + mancozeb, which resulted in the highest yield, differed from copper hydroxide, ASM - famoxadone + mancozeb, and benzalkonium chlorides. ASM and famoxadone + mancozeb were those that promoted benefit/cost relation higher than 1 .
\end{abstract}

Keywords: Solanum lycopersicum, Xanthomonas perforans, Xanthomonas gardneri, pesticides, systemic acquired resistance inducer.

\section{(Recebido para publicação em 20 de dezembro de 2011; aceito em 30 de outubro de 2012) (Received on December 20, 2011; accepted on October 30, 2012)}

\begin{abstract}
A mancha-bacteriana do tomateiro, causada por quatro espécies de Xanthomonas (X. vesicatoria, $X$. euvesicatoria, $X$. perforans e $X$. gardneri) (Jones et al., 2004), foi relatada pela primeira vez no Brasil em 1959 em municípios de São Paulo (Rodrigues Neto et al., 1984), e se tornou uma das
\end{abstract}

mais importantes doenças da cultura do tomateiro (Lopes \& Quezado-Soares, 1997). Em condições experimentais de campo, sob irrigação convencional (por aspersão), registrou-se uma redução de até $52 \%$ da produção de tomate para indústria devido à mancha-bacteriana (Quezado-Soares et al., 1998).
Os prejuízos causados por esta doença são devidos à redução da produtividade causada pela destruição foliar, com consequente perda de superfície fotossintetizante, e queda de flores e frutos em formação. Além disso, principalmente no tomate rasteiro, a destruição foliar expõe os frutos à queima pelo sol 
(escaldadura), o que afeta diretamente a qualidade dos mesmos (Lopes \& Quezado-Duval, 2005).

É uma doença de difícil controle e vários fatores contribuem para isso, tais como: eficiência variável do controle químico, com poucos produtos registrados para esse fim; indisponibilidade de cultivares com resistência adequada; rápida disseminação nas lavouras em condições favoráveis; alta umidade relativa e transmissão por sementes contaminadas (Lopes \& Quezado-Soares, 2000).

Tradicionalmente, o controle químico da mancha-bacteriana tem sido feito com antibióticos e produtos à base de cobre. No entanto, com o uso indiscriminado desses produtos pelos agricultores, populações de bactérias resistentes podem surgir, contribuindo para a ineficiência desses produtos (Lopes \& Quezado-Soares, 2000). Atualmente, além dos cúpricos, apenas os princípios ativos acibenzolar-S-metil (ASM) e cloretos de benzalcônio, possuem registro para a cultura no Ministério da Agricultura Pecuária e Abastecimento (MAPA) com indicação para o controle da mancha-bacteriana (Agrofit, 2011). O ASM é um indutor da resistência da própria planta, e os cloretos de benzalcônio são amônias quaternárias que agem por contato e induzem resistência localizada (CIETEC, 2008).

A pouca disponibilidade de produtos eficazes tem propiciado a busca por alternativas de controle da manchabacteriana, entre os produtos fungicidas já registrados para a cultura do tomateiro, como o metiram + piraclostrobina (Junior Jacobelis, 2008) e a formulação famoxadona + mancozebe. $\mathrm{O}$ metiram + piraclostrobina é registrado para o controle do oomiceto Phytophthora infestans e do fungo Septoria lycopersici. A famoxadona é uma molécula que age por contato e que compõe o produto comercial Tanos ${ }^{\circledR}$, registrado nos EUA e indicado não só para o controle da mancha-bacteriana, como da pinta bacteriana (Pseudomonas syringae pv. tomato) (Quezado-Duval, 2006; Shepherd et al., 2004). Já o mancozebe, constante nas formulações de fungicidas comercializados no Brasil, juntamente com a famoxadona, é um produto de contato de amplo espectro. Alguma eficiência para o controle da manchabacteriana em pimentão com aplicações de hidróxido de cobre mais mancozebe foi relada por Bernal \& Berger (1996) e Mccarter (1992), citados por Gullino et al. (2010). Esse princípio ativo é recomendado em mistura há muitos anos com o cobre, para melhorar a eficiência deste último (Marco \& Stall, 1983).

O controle de doenças de plantas por produtos fertilizantes, como os fosfitos, também tem sido especulado (Nascimento, 2006; Nascimento et al., 2008). Os fosfitos parecem ter ação direta e indireta sobre microrganismos, agindo como uma toxina sobre fungos e também estimulando a formação de substâncias de defesa das plantas (Dercks \& Creasy, 1989).

Nesse contexto, o objetivo deste trabalho foi avaliar em campo alguns princípios ativos com potencial de uso no controle da mancha-bacteriana do tomateiro, causada por $X$. perforans e $X$. gardneri, por serem espécies detectadas nas lavouras de tomate para processamento industrial em Goiás.

\section{MATERIAL E MÉTODOS}

Foram realizados dois ensaios na área experimental da Unilever Bestfoods, em Goiânia-GO (16³5'12'S, 49²1'14"'O, $730 \mathrm{~m}$ de altitude), de fevereiro a junho de 2007 e abril a agosto de 2008 .

No primeiro ensaio, plantou-se o híbrido Heinz 9992, em delineamento experimental de blocos ao acaso com 15 tratamentos (Tabela 1) e três repetições. As mudas foram transplantadas com trinta dias após a semeadura, com espaçamento de 1,30 m entre linhas e 0,25 m entre plantas, com parcelas de três linhas de plantio com $5 \mathrm{~m}$ de comprimento. Aárea total do experimento foi de $270 \mathrm{~m}^{2}$.

A calagem e adubação foram feitas de acordo com a análise do solo, utilizando-se a fórmula 04-30-16 na dosagem de 1,5 t ha $^{-1}$. Como adubação de cobertura utilizou-se a fórmula 18-00-27, na dosagem de $300 \mathrm{~kg} \mathrm{ha}^{-1}$.

Os tratamentos foram feitos via pulverização foliar, utilizando pulverizador costal de barra, de pressão constante, à base de $\mathrm{CO}_{2}$ com volume inicial de 300
$\mathrm{L} \mathrm{ha}^{-1}$, aumentado gradativamente o volume de aplicação até $600 \mathrm{~L} \mathrm{ha}^{-1}$, de acordo com o crescimento das plantas. $\mathrm{O}$ $\mathrm{pH}$ da água e das caldas foi medido para fins de registro, fazendo-se nenhuma correção, conforme o padrão empregado na fazenda e pelos produtores em geral. As aplicações foram realizadas em intervalos semanais, a partir dos nove dias após o transplante (dat), até os 72 dias, o que totalizou dez aplicações (Tabela 1). Foram feitas pulverizações de rotina com inseticidas e fungicidas selecionados para não interferir no controle de bacterioses para uma boa condução da lavoura. A irrigação foi via pivô central.

Quando as plantas atingiram o estádio de florescimento, aos 33 dat, foram inoculadas com isolado EH 2005-54 de $X$. perforans, oriundo da área experimental e mantido na Coleção de Bactérias Fitopatogênicas da Embrapa Hortaliças. A concentração do inóculo foi de aproximadamente $10^{6} \mathrm{ufc} / \mathrm{mL}$, que foi obtida a partir da diluição em 1:100 de uma suspensão original de $10^{8} \mathrm{ufc} / \mathrm{mL}$, cuja concentração foi ajustada em espectrofotômetro (a $600=0,3$ ). A inoculação foi feita com um pulverizador de barras mecanizado.

Avaliou-se a severidade da doença por parcela atribuindo-se notas de 1 a 5 (1= ausência ou traços da doença; $2=$ menos de $25 \%$ da área foliar lesionada, notadamente nas folhas baixeiras; $3=$ de $25-50 \%$ da área foliar lesionada; $4=$ $50-75 \%$ de folhagens lesionadas e $5=$ mais de $75 \%$ da área foliar lesionada, nas folhas mais novas) em quatro épocas (22, 33, 44 e 51 dias após a inoculação). As notas foram dadas por um único avaliador, com exceção da segunda avaliação, que foi realizada por três avaliadores independentes. Este procedimento foi realizado para verificar se havia discrepâncias entre as notas dos avaliadores. Não havendo diferença significativa entre eles $(\mathrm{F}, \mathrm{p}<0,05)$, as avaliações subsequentes foram feitas com um avaliador. Avaliou-se ainda a incidência da doença nos frutos e produtividade $\left(\mathrm{t} \mathrm{ha}^{-1}\right)$ por ocasião da colheita, aos 120 dat, ambos tomados em 12 plantas $(3 \mathrm{~m})$ da linha central de cada parcela. Os dados obtidos nas avaliações foram submetidos à análise de variância. As médias da severidade da doença nas 
folhas, incidência nos frutos e a produtividade foram comparados pelo teste Tukey a 5\%. Foram feitas a análise de correlação entre a produtividade $\left(\mathrm{t} \mathrm{ha}^{-1}\right)$ e a severidade da doença e uma análise econômica básica, denominada relação benefício/custo, onde "benefício" = (produtividade média do tratamento menos a produtividade média da testemunha, ou seja, o incremento em produtividade pela aplicação do produto) X preço da tonelada; e "custo" = quantidade do produto utilizado $\mathrm{X}$ preço do produto, mais custo de aplicação (custo de horas máquina).

No segundo ensaio foram utilizados dois híbridos, o Hypeel 108 e o U2006. O delineamento experimental foi blocos ao acaso em parcelas subdivididas, onde a variável principal foi tratamento químico e a subparcela, híbrido, utilizando-se três repetições. As mudas foram transplantadas com 29 dias após a semeadura, com espaçamento de $1,30 \mathrm{~m}$ entre linhas e $0,25 \mathrm{~m}$ entre plantas, em três linhas de plantio com $5 \mathrm{~m}$ de comprimento para cada híbrido, sendo que uma parcela era constituída de dois híbridos contendo $10 \mathrm{~m}$ de comprimento e entre os híbridos um espaçamento de $2 \mathrm{~m}$. As parcelas também foram separadas por um espaçamento de $5 \mathrm{~m}$ e o espaçamento entre os blocos foi de 2,60 m. Com este espaçamento o trator utilizado para fazer as pulverizações movimentava-se dentro do ensaio, facilitando assim as aplicações. A área total do experimento foi de $2.184 \mathrm{~m}^{2}$.

A calagem e a adubação foram realizadas como no primeiro ensaio. Os tratamentos foram feitos via pulverização foliar, utilizando um trator (Yanmar ${ }^{\circledR}$, modelo 1145-4), com um tanque de capacidade de 400 L). Como para o ensaio anterior, o $\mathrm{pH}$ das caldas foi medido para fins de registro. O comprimento da barra de pulverização foi de $4 \mathrm{~m}$, utilizando oito bicos tipo leque duplo com espaçamento de $0,50 \mathrm{~m}$ entre os bicos. Após aplicação de cada tratamento, o tanque era lavado com a utilização de um tanque de água em outro trator.

Os volumes utilizados para as aplicações variaram de $300 \mathrm{~L} \mathrm{ha}^{-1}$ até 800 $\mathrm{L} \mathrm{ha}^{-1}$. As aplicações foram realizadas em intervalos semanais, iniciando-se aos 22 dat, sendo a última pulverização realizada, aos 85 dias após o transplante, totalizando dez aplicações (Tabela 2). Como no primeiro ensaio, todas as parcelas receberam pulverizações de rotina com fungicidas e inseticidas e a irrigação foi via pivô central.

Foram feitas duas inoculações, a primeira foi aos 37 dat, com o mesmo isolado do primeiro ensaio, na concentração de aproximadamente $10^{8} \mathrm{ufc} / \mathrm{mL}$. A segunda foi aos 57 dat, utilizando o isolado EH 2006-17 de X. gardneri, na mesma concentração anterior. As inoculações foram feitas como mencionado para o primeiro ensaio.

Foram analisados a severidade da doença nas folhas, incidência da doença nos frutos, escaldadura nos frutos e produtividade. Com exceção da severidade nas folhas, as demais variáveis foram tomadas como descrito para o primeiro ensaio. Para severidade foliar realizou-se dois tipos de avaliação. A primeira foi aos 85 dat, quando se delimitou uma área com um quadro de madeira $(1,3 \mathrm{x}$ $1,0 \mathrm{~m}$ ) colocado sobre a linha central da parcela e, em seguida, foram fotografadas as plantas que estavam inseridas dentro do quadro até completar os três metros da parcela central, com o fotógrafo posicionando-se em uma escada acima da copa a uma altura de 1,80 m. Estas fotografias foram digitalizadas e avaliadas por sete técnicos da área. Para tanto, foram dadas notas que variaram de 1 a $5(1=0 \% ; 2=25 \% ; 3=50 \% ; 4=$ $75 \%$ e $5=100 \%$ de área foliar lesionada dentro do quadro). A segunda avaliação foi realizada aos 120 dat, por ocasião da colheita. Foram avaliadas seis plantas de cada parcela depois de retirados os frutos. Para esta avaliação, forrou-se o solo com um pano preto e colocaram-se três plantas de cada parcela em cima do mesmo que, em seguida foram fotografadas. Estas fotos foram avaliadas pelo programa Quant 2002 (Francisco XR do Vale; Elpídio I Fernandes Filhos; Laércio Zambolim; José R Liberato, Depto. Fitopatologia, programa computacional para quantificação de doenças, UFV, versão 1.0 Beta).

Os dados obtidos nas avaliações foram submetidos à análise de variância. As médias de severidade da doença nas folhas, a incidência nos frutos e a produtividade foram comparados pelo teste Tukey em nível 5\%. Foi feita a análise de correlação entre as variáveis. Também foi realizada uma análise econômica conforme descrita para o primeiro ensaio.

\section{RESULTADOS E DISCUSSÃO}

No primeiro ensaio, foram detectadas diferenças significativas entre os tratamentos químicos apenas para os dados de severidade na primeira $(\mathrm{p}=0,02)$ e na segunda avaliação $(p=0,04)$, mas nenhum dos tratamentos diferiu da testemunha (Tabela 3). Nessas avaliações, a menor severidade foi do tratamento 6 (ASM - famoxadona + mancozebe), que diferiu do tratamento 12 , fosfito de potássio na primeira avaliação, e do tratamento 14, hidróxido de cobre na segunda avaliação (Tabela 3 ). $\mathrm{Na}$ avaliação de frutos com sintomas da mancha-bacteriana não foram detectadas diferenças significativas nos números médios de frutos com sintomas de mancha-bacteriana $(p=0,19)$.

A produtividade média variou de 55,81 a $74,70 \mathrm{t} \mathrm{ha}^{-1}$ apresentando uma diferença de $25 \%$ de produtividade entre os tratamentos 14 (hidróxido de cobre) e 2 (ASM - hidróxido de cobre) sem no entanto terem sido detectadas diferenças significativas pela comparação de todos os tratamentos $(\mathrm{p}=0,65)$ (Tabela 3$)$.

Pela análise econômica, os tratamentos que resultaram em incremento bruto de produtividade em relação à testemunha foram: ASM - hidróxido de cobre (T2), ASM/famoxadona + mancozebe (T7) e metiram + piraclostrobina/hidróxido de cobre (T10). No entanto, nenhum desses tratamentos promoveu relação benefício/custo superior a 1 .

No segundo ensaio, as notas médias de severidade foliar na primeira avaliação variaram de 1,80 a 2,46 (Tabela 4). Diferença significativa foi detectada apenas para o fator híbrido $(\mathrm{p}=0,00)$, não se detectando diferenças a $5 \%$ de probabilidade para o tratamento químico $(p=0,08)$ e para a interação entre esses dois fatores $(p=0,37)$. 'Hypeel 108 ' foi mais suscetível do que 'U2006', com valores médios de severidade de 2,5 e 1,8, respectivamente. Na segunda avaliação de severidade, a porcentagem de área foliar lesionada no ensaio variou de 18,41 a $29,91 \%$ nos dois híbridos (Tabela 4). 
Tabela 1. Tratamentos do primeiro experimento de controle químico da mancha-bacteriana no tomateiro, princípios ativos, formulações, dosagens e combinações dos produtos (treatments of the first experiment of chemical control of the bacterial spot on tomato, active ingredients, formulations, dosages and combinations of products). Goiânia, UFG, 2007.

\begin{tabular}{|c|c|c|c|c|}
\hline $\begin{array}{l}\text { Tratamento } \\
\text { (nome comercial) }\end{array}$ & $\begin{array}{c}\text { Nome técnico } \\
\text { (ingr. ativo e formulação) }\end{array}$ & $\begin{array}{c}\text { Ingrediente ativo } \\
(\mathrm{g} / \mathrm{L}, \mathrm{kg})\end{array}$ & $\begin{array}{c}\text { Dose PC } \\
\text { (kg, L/ha) }\end{array}$ & $\begin{array}{c}\text { № de aplicações semanais/ } \\
\text { regime de aplicação }\end{array}$ \\
\hline Água & - & - & - & - \\
\hline Bion $^{\circledR}-$ Kocide $^{\circledR}$ & $\begin{array}{l}\text { acibenzolar-S-metil-hidróxido } \\
\text { de cobre (WG) }\end{array}$ & $500 \mathrm{~g} / \mathrm{kg} ; 538 \mathrm{~g} / \mathrm{kg}$ & $25 \mathrm{~g}-1,5 \mathrm{~kg}$ & $\begin{array}{l}5 \text { de cada produto/em } \\
\text { sequência }\end{array}$ \\
\hline Bion $^{\circledR} /$ Kocide $^{\circledR}$ & $\begin{array}{l}\text { acibenzolar-S-metil/hidróxido } \\
\text { de cobre (WG) }\end{array}$ & $500 \mathrm{~g} / \mathrm{kg} ; 538 \mathrm{~g} / \mathrm{kg}$ & $25 \mathrm{~g}-1,5 \mathrm{~kg}$ & 10/alternando os produtos \\
\hline Bion $^{\circledR}$ & acibenzolar-S-metil (WG) & $500 \mathrm{~g} / \mathrm{kg}$ & $25 \mathrm{~g}$ & 5 \\
\hline Bion $^{\circledR}+$ Kocide $^{\circledR 2}$ & $\begin{array}{l}\text { acibenzolar-S-metil+hidróxido } \\
\text { de cobre (WG) }\end{array}$ & $500 \mathrm{~g} / \mathrm{kg}+538 \mathrm{~g} / \mathrm{kg}$ & $25 \mathrm{~g}-1,5 \mathrm{~kg}$ & 5 \\
\hline Bion $^{\circledR}$-Midas ${ }^{\circledR}$ & $\begin{array}{l}\text { acibenzolar-S-metil- } \\
\text { famoxadona }+ \text { mancozebe }\end{array}$ & $\begin{array}{l}500 \mathrm{~g} / \mathrm{kg} ; 62,5 \mathrm{~g} / \mathrm{kg} \\
+625 \mathrm{~g} / \mathrm{kg}\end{array}$ & $25 \mathrm{~g}-1,6 \mathrm{~kg}$ & $\begin{array}{l}5 \text { de cada produto/em } \\
\text { sequência }\end{array}$ \\
\hline Bion $^{\circledR} /$ Midas $^{\circledR}$ & $\begin{array}{l}\text { acibenzolar-S-metil/ } \\
\text { famoxadona }+ \text { mancozebe }\end{array}$ & $\begin{array}{l}500 \mathrm{~g} / \mathrm{kg} ; 62,5+625 \\
\mathrm{~g} / \mathrm{kg}\end{array}$ & $25 \mathrm{~g}-1,6 \mathrm{~kg}$ & 10/alternando produtos \\
\hline $\operatorname{Midas}^{\circledR}$ & famoxadona + mancozebe & $62,5 \mathrm{~g} / \mathrm{kg}+625 \mathrm{~g} / \mathrm{kg}$ & $1,6 \mathrm{~kg}$ & 10 \\
\hline Cabrio Top ${ }^{\circledR}$ & $\begin{array}{l}\text { metiram + piraclostrobina } \\
\text { (WG) }\end{array}$ & $550 \mathrm{~g} / \mathrm{kg}+50 \mathrm{~g} / \mathrm{kg}$ & $3 \mathrm{~kg}$ & $\begin{array}{l}4 \text { aplicações durante o } \\
\text { ciclo da cultura }\end{array}$ \\
\hline Cabrio $^{\circledR} /$ Kocide $^{\circledR}$ & $\begin{array}{l}\text { metiram + piraclostrobina/ } \\
\text { hidróxido de cobre }(\mathrm{WG})\end{array}$ & $\begin{array}{l}550+50 \mathrm{~g} / \mathrm{kg} ; 538 \\
\mathrm{~g} / \mathrm{kg}\end{array}$ & $3 \mathrm{~kg}-1,5 \mathrm{~kg}$ & $\begin{array}{l}3 \text { e } 7 \text {, respectivamente de } \\
\text { cada produto }\end{array}$ \\
\hline Kocide $^{\circledR}$ & hidroxido de cobre (WG) & $538 \mathrm{~g} / \mathrm{kg}$ & $1,5 \mathrm{~kg}$ & 10 \\
\hline Nutriphite $^{\circledR}$ & $\begin{array}{l}\text { Fosfito de } \mathrm{K}\left(28 \% \text { de } \mathrm{P}_{2} \mathrm{O}_{5}\right. \\
26 \% \text { de } \mathrm{K}_{2} \mathrm{O} \text { ) (líquido) }\end{array}$ & $28 \%$ e $26 \%$ & $3 \mathrm{~L}$ & 10 \\
\hline Redshield $750^{\circledR}$ & óxido cuproso (WP) & $860 \mathrm{~g} / \mathrm{kg}$ & $2,4 \mathrm{~kg}$ & 10 \\
\hline Supera $^{\circledR}$ & hidróxido de cobre (SC-líquido) & $537,44 \mathrm{~g} / \mathrm{L}$ & $3,0 \mathrm{~kg}$ & 10 \\
\hline Garra $450^{\circledR}$ & hidróxido de cobre (WP) & $691 \mathrm{~g} / \mathrm{kg}$ & $3,0 \mathrm{~kg}$ & 10 \\
\hline
\end{tabular}

${ }^{1} \mathrm{WG}=$ granulado dispersível; $\mathrm{SC}=$ suspensão concentrada; $\mathrm{WP}=$ pó molhável; ${ }^{2}$ mistura em tanque $\left({ }^{1} \mathrm{WG}=\right.$ water dispersive granules; $\mathrm{SC}=$ suspension concentrated; $\mathrm{WP}=$ wettable powder; ${ }^{2}$ mixture in tank).

Diferenças significativas não foram detectadas a $5 \%$ de probabilidade em nenhum dos componentes da variância: híbridos ( $\mathrm{p}=0,21)$, tratamentos químicos $(p=0,36)$ e a interação entre os dois fatores $(p=0,96)$. 'Hypeel 108' apresentou severidade média de $23,06 \%$, enquanto a do 'U2006' foi de $19,88 \%$.

No número de frutos com sintomas de mancha-bacteriana, foi detectada diferença significativa apenas para o fator híbrido $(\mathrm{p}=0,00)$, não se detectando diferenças a $5 \%$ para tratamentos químicos $(\mathrm{p}=0,92)$ e para a interação entre os dois fatores $(p=0,94)$. 'U2006' foi mais suscetível do que o híbrido Hypeel 108, com valores médios de 6,96 e 1,86, respectivamente. Este fato sugere que o controle genético da resistência em planta seja diferente da resistência em frutos, já que o posicionamento das variedades foi inverso com relação aos dados de severidade em planta.

$\mathrm{Na}$ avaliação de frutos com sintomas de escaldadura, diferença significativa foi detectada para híbridos $(\mathrm{p}=0,01)$ e para a interação entre os dois fatores $(\mathrm{p}=0,01)$, não se detectando diferenças a $5 \%$ para o fator tratamento químico $(p=0,36)$. Considerando o fator híbrido e a significância da interação, com exceção dos tratamentos 8 (fosfito/Supra $\mathrm{Cu}$ ) e 9 (fosfito de $\mathrm{K}$ ), o híbrido Hypeel 108 teve maior número de frutos com escaldadura do que o híbrido U 2006.

A produtividade média variou de
$73,16 \mathrm{t} \mathrm{ha}^{-1}$ a $122,31 \mathrm{t} \mathrm{ha}^{-1}$ (Tabela 4). Diferenças significativas foram detectadas tanto para o fator híbrido $(\mathrm{p}=0,00)$ como para o fator tratamento químico $(p=0,00)$, sem interação significativa entre estes dois fatores $(p=0,31)$. O híbrido U2006 foi mais produtivo do que 'Hyppel 108', com médias 108,90 t ha ${ }^{-1}$ e $82,70 \mathrm{t} \mathrm{ha}^{-1}$, respectivamente.

Apesar de terem sido detectadas diferenças significativas entre os tratamentos do fator da parcela principal, nenhum dos produtos químicos aplicados diferiram da testemunha $(99,79$ $\mathrm{t} \mathrm{ha}^{-1}$ ). O tratamento 7 (famoxadona + mancozebe), que resultou em maior produtividade $\left(109,62 \mathrm{t} \mathrm{ha}^{-1}\right)$, diferiu significativamente dos tratamentos 
Tabela 2. Tratamentos do segundo experimento de controle químico da mancha-bacteriana do tomateiro, princípios ativos, formulações, dosagens e combinações dos produtos (treatments of the second experiment of chemical control of tomato bacterial spot, active ingredients, formulations, dosages and combinations of products). Goiânia, UFG, 2008.

\begin{tabular}{|c|c|c|c|c|}
\hline $\begin{array}{c}\text { Tratamento } \\
\text { (nome comercial) }\end{array}$ & $\begin{array}{c}\text { Nome técnico } \\
\text { (ingred. ativo e formulação) }\end{array}$ & $\begin{array}{l}\text { Ingrediente ativo } \\
(\mathrm{g} / \mathrm{L}, \mathrm{kg})\end{array}$ & $\begin{array}{c}\text { Dose PC } \\
(\mathrm{kg}, \mathrm{L} / \mathrm{ha})\end{array}$ & $\begin{array}{l}\text { № de aplicações } \\
\text { semanais/regime } \\
\text { de aplicação }\end{array}$ \\
\hline água & - & - & - & - \\
\hline Bion $^{\circledR}-$ Kocide $^{\circledR}$ & acibenzolar-S-metil-hidróxido de cobre & $500 \mathrm{~g} / \mathrm{kg} 538 \mathrm{~g} / \mathrm{kg}$ & $25 \mathrm{~g}-1,5 \mathrm{~kg}$ & $\begin{array}{l}5 \text { de cada produto/ } \\
\text { em sequência }\end{array}$ \\
\hline Bion $^{\circledR}$ & acibenzolar-S-metil (WG) & $500 \mathrm{~g} / \mathrm{kg}$ & $25 \mathrm{~g}$ & $\begin{array}{l}\text { 10/alternando os } \\
\text { produtos }\end{array}$ \\
\hline Kocide $^{\circledR}$ & hidróxido de cobre (WG) & $538 \mathrm{~g} / \mathrm{kg}$ & $1,5 \mathrm{~kg}$ & 5 \\
\hline Fegatex $^{\circledR}$ & cloretos de benzalcônio (SL) & $100 \mathrm{~g} / \mathrm{L}$ & $3 \mathrm{~L}$ & 10 \\
\hline Bion $^{\circledR}-$ Midas $^{\circledR}$ & $\begin{array}{l}\text { acibenzolar-S-metil-famoxadona }+ \\
\text { mancozebe }\end{array}$ & $538 \mathrm{~g} / \mathrm{kg}$ & $25 \mathrm{~g}-1,6 \mathrm{~kg}$ & 10 \\
\hline $\operatorname{Midas}^{\circledR}$ & famoxadona + mancozebe (WG) & $62,5+625 \mathrm{~g} / \mathrm{kg}$ & $1,6 \mathrm{~kg}$ & $\begin{array}{l}5 \text { de cada produto/ } \\
\text { em sequência }\end{array}$ \\
\hline Reforce $^{\circledR} /$ Supra Cu ${ }^{\circledR}$ & $\begin{array}{l}\text { Fosfito }\left(25,6 \% \text { de } \mathrm{P}_{2} \mathrm{O}_{5} ; 17,8 \% \text { de } \mathrm{K}_{2} \mathrm{O}\right) / \\
\text { Supra } \mathrm{Cu}\end{array}$ & $25,6 \%$ e $17 \%$ & $3 \mathrm{~L}$ & 10 \\
\hline Hortifós PK ${ }^{\circledR}$ & $\begin{array}{l}\text { Fosfito de } \mathrm{K}\left(28 \% \text { de } \mathrm{P}_{2} \mathrm{O}_{5} ; 26 \% \text { de }\right. \\
\left.\mathrm{K}_{2} \mathrm{O}\right) \text { (líquido) }\end{array}$ & $28 \%$ e $26 \%$ & $3 \mathrm{~L}$ & $\begin{array}{l}5 \text { de cada produto/ } \\
\text { em sequência }\end{array}$ \\
\hline Cabrio Top ${ }^{\circledR}$ & metiram + piraclostrobina $(\mathrm{WG})$ & $550+50 \mathrm{~g} / \mathrm{kg}$ & $3 \mathrm{~kg}$ & $\begin{array}{l}4 \text { aplicações durante } \\
\text { o ciclo da cultura }\end{array}$ \\
\hline
\end{tabular}

${ }^{1} \mathrm{WG}=$ granulado dispersível; $\mathrm{SC}=$ suspensão concentrada; $\mathrm{WP}=$ pó molhável $\left({ }^{1} \mathrm{WG}=\right.$ water dispersive granules; $\mathrm{SC}=$ suspension concentrated; $\mathrm{WP}=$ wettable powder; ${ }^{2}$ mixture in tank).

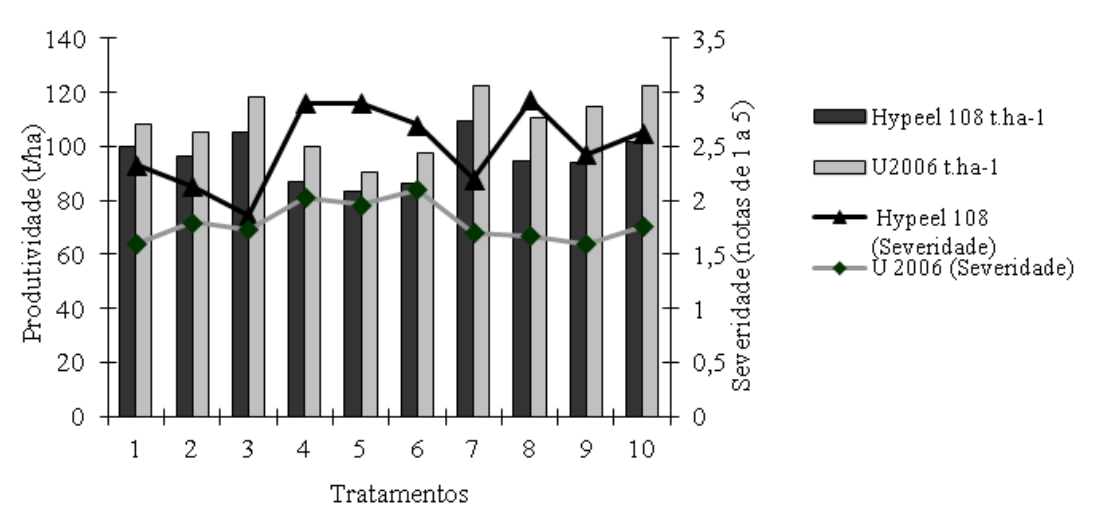

Figura 1. Correlação entre as médias da severidade da mancha-bacteriana nas folhas com a produtividade do tomateiro. $1=$ testemunha, $2=$ acibenzolar-S-metil-hidróxido de cobre, $3=$ acibenzolar-S-metil, $4=$ hidróxido de cobre, $5=$ cloretos de benzalcônio, $6=$ acibenzolarS-metil - famoxadone + mancozebe, $7=$ famoxadone + mancozebe, $8=$ fosfito/supra $\mathrm{Cu}, 9=$ fosfito de K, 10= metiram + pyraclostrobin (correlation among mean of severity of bacterial spot on the leaves and yield. 1= control, 2= acibenzolar-S-methyl - copper hydroxide, $3=$ acibenzolar-S-methyl, 4= copper hydroxide, $5=$ benzalkonium chloride, $6=$ acibenzolar-Smethyl - famoxadone + mancozeb, $7=$ famoxadone + mancozeb, $8=$ phosphite $/$ supra $\mathrm{Cu}, 9=$ phosphite of K, 10= metiram + pyraclostrobin). Goiânia, UFG, 2008.

4 (hidróxido de cobre), 5 (cloreto de benzalcônio) e 6 (ASM - famoxadona + mancozebe). Estes tratamentos, que não diferiram entre si, foram os menos produtivos.

Entre as correlações realizadas para todas as variáveis, somente produtividade e severidade (notas tomadas aos 85 dias após o transplante das mudas para o campo) tanto para 'Hypeel 108 ' quanto para 'U2006', foi significativa ( $\mathrm{p}=0,00$ para ambos) e negativa ( $\mathrm{r}=-0,58$ e $\mathrm{r}=$ $-0,47$, respectivamente). Para 'Hypeel $108^{\prime}$ o valor do $r^{2}=0,34$ o que significa que $34 \%$ da variação da produtividade é explicada pela variação da severidade estimada pelas notas e para 'U2006' o valor do $r^{2}=0,22$, significando que $22 \%$ da variação da produtividade é explicada também pela variação das severidades estimadas pelas notas, demostrando que o híbrido Hypeel 108 é mais suscetível à mancha-bacteriana do que o híbrido U2006 (Figura 1).

Os tratamentos que resultaram em incremento de produtividade em relação à testemunha foram: ASM (T3), famoxadona + mancozebe (T7) e metiram + piraclostrobina / hidróxido de cobre (T10). De acordo com a análise econômica, os tratamentos ASM (T3) e famoxadona + mancozebe (T7) também promoveram uma relação benefício/ custo superior a 1 , com 1,74 e 1,28 respectivamente. 
Tabela 3. Severidade da mancha-bacteriana em folhas, número de frutos com sintomas e produtividade do tomateiro (híbrido Heinz 9992), em função dos tratamentos químicos (severity of the bacterial spot in leaves, number of fruits with symptoms and productivity of the tomato hybrid Heinz 9992, depending on the chemical treatments). Goiânia, UFG, 2008.

\begin{tabular}{|c|c|c|c|c|c|c|}
\hline \multirow[b]{2}{*}{ Tratamento } & \multicolumn{4}{|c|}{ Severidade (notas de 1 a 5 ) } & \multirow{2}{*}{$\begin{array}{c}\text { Frutos com } \\
\text { sintomas (média/12 } \\
\text { plantas) }\end{array}$} & \multirow[b]{2}{*}{$\begin{array}{l}\text { Produtividade } \\
\text { (t/ha) }\end{array}$} \\
\hline & $\begin{array}{l}22 \text { DAI* }^{*} \\
(19 / 04)\end{array}$ & $\begin{array}{l}33 \text { DAÍ } \\
(30 / 04)\end{array}$ & $\begin{array}{l}\text { 44 DAI } \\
(11 / 05)\end{array}$ & $\begin{array}{l}\text { 51 DAI } \\
(18 / 05)\end{array}$ & & \\
\hline água & $2,73 \mathrm{ab}$ & $3,66 \mathrm{ab}$ & $3,66 \mathrm{~ns}^{3}$ & $3,83 \mathrm{~ns}$ & $70,00 \mathrm{~ns}$ & $72,20 \mathrm{~ns}$ \\
\hline ASM-hidróxido de cobre (WG) & $2,33 \mathrm{ab}$ & $3,33 \mathrm{ab}$ & 4,00 & 4,00 & 63,00 & 74,70 \\
\hline ASM/hidróxido de cobre (WG) & $2,60 \mathrm{ab}$ & $3,50 \mathrm{ab}$ & 3,50 & 3,83 & 45,33 & 61,88 \\
\hline ASM & $3,16 \mathrm{ab}$ & $4,00 \mathrm{ab}$ & 4,00 & 3,66 & 42,33 & 59,32 \\
\hline ASM+hidróxido de cobre $(\mathrm{WG})^{2}$ & $2,50 \mathrm{ab}$ & $4,00 \mathrm{ab}$ & 4,33 & 4,50 & 36,33 & 57,86 \\
\hline ASM/famoxadona + mancozebe & $2,26 \mathrm{~b}$ & $2,66 \mathrm{~b}$ & 3,66 & 3,50 & 45,00 & 69,40 \\
\hline ASM/famoxadona + mancozebe & $2,76 \mathrm{ab}$ & $3,16 \mathrm{ab}$ & 3,66 & 3,50 & 59,00 & 73,51 \\
\hline famoxadona + mancozebe & $2,63 \mathrm{ab}$ & $4,16 \mathrm{ab}$ & 4,16 & 3,66 & 68,00 & 58,03 \\
\hline Metiram + piraclostrobina & $2,93 \mathrm{ab}$ & $3,83 \mathrm{ab}$ & 3,83 & 3,66 & 66,33 & 70,34 \\
\hline $\begin{array}{l}\text { metiram + piraclostrobina/hidróxi- } \\
\text { do de cobre (WG) }\end{array}$ & $2,63 \mathrm{ab}$ & $3,83 \mathrm{ab}$ & 3,83 & 4,00 & 51,33 & 72,31 \\
\hline hidróxido de cobre (WG) & $2,83 \mathrm{ab}$ & $3,00 \mathrm{ab}$ & 3,83 & 3,83 & 79,67 & 70,85 \\
\hline Fosfito de K & $3,33 \mathrm{a}$ & $3,66 \mathrm{ab}$ & 4,16 & 3,83 & 42,67 & 62,05 \\
\hline óxido cuproso (WP) & $2,93 \mathrm{ab}$ & $4,00 \mathrm{ab}$ & 3,66 & 4,00 & 83,67 & 63,51 \\
\hline Hidróxido de cobre (SC) & $3,13 \mathrm{ab}$ & $4,50 \mathrm{a}$ & 4,00 & 4,16 & 52,33 & 55,81 \\
\hline hidróxido de cobre (WP) & $3,06 \mathrm{ab}$ & $3,66 \mathrm{ab}$ & 3,50 & 3,50 & 79,67 & 64,79 \\
\hline $\mathrm{CV}(\%)$ & 11,92 & 15,92 & 12,83 & 11,87 & 37,15 & 18,86 \\
\hline
\end{tabular}

*DAI= Dias após a inoculação; ${ }^{1} \mathrm{WG}=$ granulado dispersível; $\mathrm{SC}=$ suspensão concentrada; $\mathrm{WP}=$ pó molhável; ${ }^{2}$ mistura em tanque $(* \mathrm{DAI}=$ Days after inoculation; ${ }^{1} \mathrm{WG}=$ water dispersable granules; $\mathrm{SC}=$ suspension concentrated; $\mathrm{WP}=$ wettable powder; ${ }^{2}$ mixture in tank).

Poucos trabalhos têm sido publicados relatando avaliações de produtos químicos para o controle da mancha-bacteriana em lavouras de tomate para processamento industrial no Brasil (Maringoni et al., 1986; Quezado-Soares et al., 1998; Quezado-Duval et al., 2005) e no mundo (Lewis et al., 2005). Além disso, provavelmente em razão da grande variedade de tomateiros e patógenos, não se encontram metodologias normatizadas para a realização de tais testes. Dentre os fatores a serem considerados para uma padronização de metodologia menciona-se o tamanho das parcelas, espaçamento e dados a serem tomados que demonstrem a ação de controle. Para a mancha-bacteriana do tomateiro, em geral são tomados dados de severidade e de produtividade (Maringoni et al., 1986).

Dados tomados ao logo do tempo podem ser utilizados para o cálculo da Área Abaixo da Curva de Progresso da Doença (AACPD) e do Componente Principal, o que permite resumir as variáveis representadas por épocas de leitura sem grandes perdas de informa- ção e tem permitido a diferenciação de genótipos quanto à resistência (Mello et al., 1997) e de produtos quanto à eficiência no controle da mancha-bacteriana (Quezado-Duval et al., 2005). No entanto, a comparação entre este tipo de abordagem em relação a uma tomada de dado pontual em determinada época no ciclo da cultura ainda não foi feita para o patossistema estudado. Para o tomate rasteiro, de crescimento determinado, há ainda a dificuldade no manuseio das plantas, que poderia levar a danos, influenciando os resultados de produtividade, sendo interessante e mais viável a tomada do dado na parcela como um todo. Este fato deve ser considerado na escolha da unidade de observação que poderia ser uma ou mais folhas (Maringoni et al., 1986; Mello et al., 1997; Quezado-Duval et al., 2005) ou folíolos da planta inteira (Mello et al., 1997), ou a parcela como um todo.

Deste modo, no presente trabalho, três metodologias foram desenvolvidas e utilizadas para a avaliação da severidade, na tentativa de aprimorá-la a cada ensaio. Para quantificar a doença, além da severidade foliar, alguns autores têm utilizado a quantidade de frutos com sintomas da doença (Maringoni et al., 1986; Quezado-Duval et al., 2005), o que também foi registrado no presente trabalho, acrescentando-se a escaldadura como um possível resultado da severidade da doença. A variação entre as metodologias de avaliação da severidade e os resultados obtidos neste trabalho, onde diferentes metodologias foram desenvolvidas e utilizadas nos distintos experimentos, indicam a necessidade de ajuste e padronização da mesma para tomada dessa variável em tomate rasteiro.

Em nenhum dos experimentos foi possível atestar a eficiência do controle químico, em termos de redução de severidade foliar, em relação à testemunha. No entanto, alguns tratamentos indicaram uma tendência em reduzir a doença, tais como acibenzolar-S-metil em combinação com famoxadona + mancozebe no primeiro experimento e acibenzolar-S-metil (primeira avaliação) e acibenzolar-S-metil - hidróxido de cobre, no segundo experimento. $\mathrm{O}$ 
Tabela 4. Severidade da mancha-bacteriana em folhas (avaliação por notas e porcentagem), número de frutos com sintomas da manchabacteriana, número de frutos com sintomas de escaldadura e produtividade do tomateiro dos híbridos Hypeel 108 e U 2006 , em função dos tratamentos [severity of the bacterial spot in leaves (evaluation for notes and percentage), number of fruits with symptoms of the bacterial spot, number of fruits with scalding symptoms and yield the hybrids Hypeel 108 and U 2006, depending on chemical treatments]. Goiânia, UFG, 2008.

\begin{tabular}{|c|c|c|c|c|c|c|c|}
\hline \multirow[b]{2}{*}{ Tratamento } & \multirow[b]{2}{*}{$\begin{array}{c}\text { Severidade } \\
(84 \text { DAT })^{1}\end{array}$} & \multirow{2}{*}{$\begin{array}{l}\text { Doença na } \\
\text { planta (\%) } \\
(120 \text { DAT) }\end{array}$} & \multirow{2}{*}{$\begin{array}{c}\text { Frutos com sin- } \\
\text { tomas }\left(n^{0}\right) \text { em } 12 \\
\text { plantas (120 DAT) }\end{array}$} & \multirow{2}{*}{$\begin{array}{c}\text { Frutos com sintomas } \\
\text { de escaldadura }\left(n^{0}\right) \\
(120 \text { DAT })\end{array}$} & \multicolumn{3}{|c|}{ Produtividade (t/ha) (120 DAT) } \\
\hline & & & & & $\begin{array}{c}\text { Hypeel } \\
108\end{array}$ & $\begin{array}{c}\mathrm{U} \\
2006\end{array}$ & Média \\
\hline água & $1,96 \mathrm{~ns}^{2}$ & $24,91 \mathrm{~ns}$ & $4,00 \mathrm{~ns}$ & $9,00 \mathrm{~ns}$ & 91,54 & 108,03 & $99,79 \mathrm{abc}$ \\
\hline $\begin{array}{l}\text { ASM-hidróxido } \\
\text { de cobre }\end{array}$ & 1,96 & 15,29 & 1,00 & 11,00 & 87,52 & 105,04 & $96,28 \mathrm{abc}$ \\
\hline ASM & 1,80 & 21,37 & 3,00 & 9,00 & 92,91 & 118,03 & $105,47 \mathrm{ab}$ \\
\hline $\begin{array}{l}\text { hídroxido de } \\
\text { cobre }\end{array}$ & 2,46 & 17,52 & 3,00 & 15,00 & 73,59 & 99,91 & $86,75 \mathrm{bc}$ \\
\hline $\begin{array}{l}\text { cloreto de ben- } \\
\text { zalcônio }\end{array}$ & 2,41 & 24,11 & 4,00 & 14,00 & 76,67 & 90,26 & $83,46 \mathrm{c}$ \\
\hline $\begin{array}{l}\text { ASM-famoxado- } \\
\text { na + mancozebe }\end{array}$ & 2,40 & 21,89 & 2,00 & 12,00 & 75,21 & 97,44 & $86,32 \mathrm{bc}$ \\
\hline $\begin{array}{l}\text { famoxadona }+ \\
\text { mancozebe }\end{array}$ & 1,95 & 18,41 & 2,00 & 9,00 & 96,92 & 122,31 & 109,62 a \\
\hline fosfito/supra $\mathrm{Cu}$ & 2,30 & 18,99 & 8,00 & 10,00 & 79,15 & 110,34 & $94,74 \mathrm{abc}$ \\
\hline fosfito de $\mathrm{K}$ & 2,18 & 29,91 & 3,00 & 14,00 & 73,16 & 114,79 & $93,97 \mathrm{abc}$ \\
\hline $\begin{array}{l}\text { metiram + pira- } \\
\text { clostrobina }\end{array}$ & 2,20 & 22,53 & 7,00 & 13,00 & 80,77 & 122,39 & $101,58 \mathrm{abc}$ \\
\hline CV (\%) & 44,44 & 18,97 & 42,92 & 47,09 & - & - & 11,26 \\
\hline
\end{tabular}

${ }^{\mathrm{I}} \mathrm{DAT}=$ dias após o transplante, severidade avaliada por escala de notas de 1 a $5 ;{ }^{2} \mathrm{~ns}=$ não significativo a $5 \%$ ('DAT= days after transplanting, severity evaluated through grades from 1 to $5 ;{ }^{2} \mathrm{~ns}=$ not significant at $5 \%$ ).

pH da água de preparação da calda foi de 6,1 no primeiro ensaio e de 8,6 no segundo ensaio. No primeiro ensaio, com exceção do Nutriphite, que teve pH 6,8, as caldas de Bion ${ }^{\circledR}+$ Kocide $^{\circledR}$, Bion $^{\circledR}$, Kocide $^{\circledR}$, Midas $^{\circledR}$, Cabrio Top ${ }^{\circledR}$, Redshield $^{\circledR}$, Supera ${ }^{\circledR}$ e Garra $^{\circledR}$ foram básicas (valores de 7,2 a 8,9). No segundo ensaio, as caldas de Reforce ${ }^{\circledR}$, Cabrio Top ${ }^{\circledR}$, Hortifós ${ }^{\circledR}$ e Bion $^{\circledR}$ foram ligeiramente ácidas $(5,9,6,4,6,7 \mathrm{e}$ $6,9)$, enquanto as de Midas ${ }^{\circledR}$, Fegatex $^{\circledR}$, Supra $\mathrm{Cu}^{\circledR}$ e Kocide $^{\circledR}$, foram básicas $(7,8,8,2,8,9$ e 9,4). De modo geral, os produtos fitossanitários apresentam maior eficiência quando as caldas são um pouco ácidas, com $\mathrm{pH}$ entre 6,0 e 6,5 (Kissmann, 1998). No entanto, outros autores citam que uma correção do $\mathrm{pH}$ da água para valores ligeiramente ácidos é o procedimento a adotar no preparo das caldas de agrotóxicos (Villas Bôas $\&$ Castelo Branco, 2009). No presente trabalho, optou-se por não alterar esse fator, já que a prática não era adotada na fazenda, nem usualmente observada entre produtores, segundo informação dos técnicos das empresas processadoras.
Além disso, considera-se que para cada produto deva haver uma condição ideal de $\mathrm{pH}$, informação que não está disponível aos produtores. Porém, observou-se variações tanto da água usada no preparo da calda, como na calda resultante, de um ano para outro, o que indica que trabalhos devem ser conduzidos para cada produto com potencial de controle em diferentes $\mathrm{pH}$ no sentido de orientar melhor os produtores.

Considerando-se os resultados de ambos os ensaios, ressalta-se que, enquanto o tratamento ASM - famoxadona + mancozebe foi o melhor no primeiro, com valor de severidade inferior à testemunha, no segundo apresentou comportamento distinto, dependendo da avaliação (por nota-85 dias após transplante e porcentagem-colheita). Neste experimento, ASM apresentou o menor valor na primeira avaliação (notas) e o ASM - hidróxido de cobre na segunda (\%). Vários trabalhos têm atestado a eficiência do ASM no controle de doenças, inclusive da mancha-bacteriana do tomateiro (Paradela et al., 2001; Lewis et al., 2005; Obradovic et al., 2005), como também para pinta-bacteriana (Pitblado, 2001).

$\mathrm{O}$ acibenzolar-S-metil é um produto químico indutor de resistência sistêmica adquirida, que após ser absorvido e translocado por toda parte da planta, ativa genes de defesa. No Brasil, registrado no MAPA como Bion ${ }^{\circledR}$, o produto é indicado para proteção contra doenças bacterianas em tomateiro, Moniliophthora (Crinipellis) perniciosa em mudas de cacau e Xyllela fastidiosa em mudas de citros (Silva, 2002). Em experimentos realizados com aplicações de ASM em tomateiro foram notados reduções significativas da mancha-bacteriana (Inbar et al. 1998; Silva, 2002).

Os resultados do presente trabalho ainda não permitem confirmar essa eficiência nas condições de cultivo do tomate para processamento industrial em Goiás, mas observa-se uma tendência de que o ASM sozinho ou combinado com hidróxido de cobre ou com famoxadona + mancozebe venha a reduzir a severidade da doença. Em relação à combinação durante o calendário de aplicação verificou-se comportamento 
contraditório entre os dois experimentos, tanto para severidade como para produtividade. Novos estudos precisam ser realizados para elucidar a inconsistência de alguns resultados.

A utilização do ASM em combinação com outros produtos tem sido avaliada em outros trabalhos (Lewis et al., 2005), porém em mistura de tanque e não em combinações de aplicações ao longo do ciclo da cultura, como no presente trabalho.

De maneira geral, os fungicidas à base de cobre, nas concentrações e intervalos de aplicações utilizados nos dois experimentos, não apresentaram resultados satisfatórios no controle da mancha-bacteriana. Resultado semelhante foi observado por Maringoni et al. (1986) ao avaliar diferentes fungicidas e antibióticos no controle da mancha-bacteriana em condições de campo. Segundo os autores, os fungicidas cúpricos não reduziram a área foliar e também não aumentaram significativamente a produtividade. A sensibilidade ao princípio ativo, característica intrínseca das estirpes do patógeno, é fato documentado em relação a antibióticos e ao cobre (Marco \& Stall, 1983; Quezado-Duval et al., 2005). Ainda não se conhece a sensibilidade in vitro dos isolados utilizados nos dois experimentos aos produtos aplicados. Tal informação ajudaria a elucidar a baixa eficiência de certos produtos.

Para a produtividade, observou-se que o ASM, apesar de não ter se diferenciado significativamente dos demais tratamentos, no primeiro ensaio foi o que proporcionou maior produtividade e no segundo, o que proporcionou a segunda maior produtividade. Poucos trabalhos de avaliação da eficiência de tratamentos de controle químico da mancha-bacteriana têm demonstrado diferenças estatísticas na variável produtividade.

Apesar da correlação entre severidade e produtividade ter sido significativa no segundo ensaio, para ambos os híbridos, a relação entre a ação na redução de severidade e a produtividade parece não ser uma constante nos ensaios envolvendo aplicações de ASM. Jones et al. (2005) observaram que as aplicações de ASM foram eficientes em reduzir a severidade da mancha-bacteriana, sem no entanto aumentar significantemente a produtividade nas parcelas. Romero et al. (2001) observaram efeito negativo na produção de pimentão (Capsicum annumm) quando o ASM foi aplicado intensivamente (oito aplicações durante o ciclo da cultura, semanalmente) para o controle da mancha-bacteriana; este efeito foi conseqüência da redução do número de gemas florais e do atraso na maturação de frutos. A ação de redução de severidade sem implicação em aumento de produtividade foi relatada em melão (Rizzo et al., 2003) e tomate (Paradela et al., 2001; Lewis et al., 2005; Quezado-Duval et al., 2005).

O número de aplicações de ASM poderia interferir no efeito negativo sobre a produtividade. De fato, Quezado-Duval et al. (2005) relataram que, em um ensaio de tomate para processamento industrial em campo com a variedade AP533, apesar de resultar em menor área de progresso da doença, em 10 aplicações semanais, o ASM resultou na menor produtividade do ensaio, não diferindo da testemunha não pulverizada. Também Paradela et al. (2001), em tomate envarado, observaram bons resultados em reduzir a severidade com o emprego do ASM em cinco e sete aplicações sem ação efetiva na produtividade.

O híbrido U2006 apresentou menor severidade e menor número de frutos com escaldadura em relação ao Hypeel 108, o que corrobora com a indicação dos técnicos da empresa Unilever de que este material seria mais tolerante à mancha-bacteriana, sendo por isso posicionado pelas empresas para os primeiros plantios do ano, quando as condições ambientais são mais favoráveis ao desenvolvimento da doença. Vale ressaltar no entanto, a ausência de relatos acerca da tolerância de 'U2006' em relação a cada espécie do complexo da mancha-bacteriana. No presente relato optou-se por avaliá-lo frente às espécies $X$. perforans e X. gardneri, uma vez que essas espécies foram as de maior ocorrência nas lavouras de tomate para processamento industrial em Goiás (Quezado-Duval et al., 2005).

Os resultados dos ensaios realizados não permitiram a comprovação dos resultados de um ensaio anterior, onde se observou uma tendência da aplicação de produtos à base de fosfitos, na redução da severidade de uma infecção natural da mancha-bacteriana em campo (Nascimento et al., 2008). Além disso, a utilização do fosfito não incrementou a produtividade nesse e nos realizados no presente trabalho.

O tratamento com metiram + piraclostrobina, mesmo não apresestando diferenças significativas, resultou, nos dois ensaios, na segunda maior produtividade registrada (70 $\mathrm{t} \mathrm{ha}^{-1}$ e 101 $\mathrm{t} \mathrm{ha}^{-1}$, respectivamente). Este produto pertence à linha F500 (piraclostrobina), que proporcionou aumento médio na produtividade, bem como na qualidade das lavouras, resultando em plantas mais saudáveis, com folhas mais verdes. $\mathrm{O}$ efeito fisiológico do F500 é a combinação de processos benéficos dentro da planta que resultam no aumento da fotossíntese líquida e da atividade da enzima nitrato-redutase, além da diminuição da síntese do etileno. Todos esses fatores reunidos contribuem para o aumento da produtividade e qualidade das lavouras (Galvino, 2008). Famoxadona + mancozebe apresentou maior produtividade, que diferiu significativamente do tratamento cloretos de benzalcônio. A ação da molécula famoxadona é por contato presente em um fungicida registrado nos EUA, o Tanos ${ }^{\circledR}$ (famoxadona + cimoxamil) para o controle, entre outras doenças, da mancha-bacteriana e da pinta bacteriana.

Lewis et al. (2005) obtiveram bom controle da mancha-bacteriana e outras doenças em um programa de pulverização foliar combinando pulverizações de ASM e pulverizações com $\operatorname{Tanos}^{\circledR}$ em mistura com hidróxido de cobre e mancozebe em alternância com hidróxido de cobre misturado ao mancozebe apenas. No entanto, não foram detectadas diferenças significativas em produtividade, apenas na porcentagem de frutos comercializáveis.

Já os cloretos de benzalcônio, que só foram empregados no segundo ensaio, resultaram no menor valor médio de produtividade, mas distinto da famoxadona + mancozebe (maior valor de produtividade). No entanto, apesar de ser um produto registrado com indicação para mancha-bacteriana, ainda não se 
pode fazer maiores inferências sobre sua eficiência. Além disso, não foram encontrados na literatura outros resultados de ensaios relativos a produtos à base de amônias quaternárias para o controle da mancha-bacteriana do tomate em campo, apenas relatos preliminares de sua ação in vitro e em casa de vegetação (Souza, 2006).

Em relação aos dados obtidos na análise econômica, ressalta-se que não foram encontrados trabalhos na literatura onde esta abordagem é realizada, talvez em razão da flutuação dos preços tanto da tonelada do tomate como dos produtos. Ressalta-se aqui que um possível aumento de eficiência no controle pelo incremento de um produto, em mistura ou em mais aplicações, vai também resultar em um aumento no custo e que a relação benefício/custo deve ser superior a 1 para apresentar vantagem econômica. Desse modo, no presente trabalho, os dados do primeiro ensaio indicam que naquela situação, a aplicação dos produtos não resultaria em vantagem econômica ao produtor, já que a relação benefício/custo não foi superior a 1 , naqueles poucos tratamentos onde os produtos incrementaram em valor bruto a produtividade em relação à da testemunha (ASM - hidróxido de cobre, ASM / famoxadona + mancozebe, metiram + piraclostrobina / hidróxido de cobre). Por outro lado, nas condições do segundo ensaio, os produtos que apresentaram vantagem econômica foram apenas o ASM e o famoxadona + mancozebe. A análise é interessante para subsidiar a tomada de decisão por parte do produtor/técnicos da assistência na aplicação ou não dos produtos.

\section{AGRADECIMENTOS}

Às instituições que apoiaram este projeto de pesquisa: Coordenação de Aperfeiçoamento de Pessoal de Nível Superior (CAPES), Unilever Bestfoods, Embrapa Hortaliças e Universidade Federal de Goiás.

\section{REFERÊNCIAS}

AGROFIT. Departamento de Defesa e Inspeção Vegetal. Ministério da Agricultura, Pecuária e Abastecimento. 2011, 29 de dezembro. Agrofit on line Disponível em: http//:www.agricultura. gov.br/agrofit/

CIETEC. Inovações e empreendedorismo. 2010, 31 de outubro. Aprovado primeiro defensivo agrícola nacional para uso no cultivo de cenouras, tomates e batatas. Disponível em: http://www.cietec.org.br/ index.php?id $1=30 \& \mathrm{id} 2=130$

DERCKS W; CREASY LL. 1989. Influence of fosetyl-Al on phytoalexin accumulation in the Plasmopara viticola-grapevine interaction. Physiological and Molecular Plant Pathology 34: 203-213.

GALVINO SBF. 2008. Efeito de fungicida na produção de batata e na disseminação de vírus e detecção dos variantes genéticos PVYn-wi e NE-11 no Brasil. Lavras: UFLA. 42p (Dissertação mestrado).

GULLINO ML; TINIVELLA F; GARIBALDI A; KEMMITT GM; BACCI L; SHEPPARD B. 2010. Mancozeb: Past, Present, and Future. Plant Disease 94: 1076-1087.

INBAR M; DOOSTAR H; SONODA RM; LEIBEE GL; MAYER T. 1998. Elicitors of plant defensive system reduce insect densities and disease incidence. Journal of Chemical Ecology 24: 135-149.

JONES JB MOMOL MT; OBRADOVIC A; BALOGH B; OLSON SM. 2005. Bacterial spot management on tomatoes. Acta Horticulturae 695: 119-123.

JONES JB; LACY GH; BOUZAR H; STALL RE; SCHAAD NW. 2004. Reclassification of the xanthomonads associated with bacterial spot disease of tomato and pepper. Systematic and Applied Microbiology 27: 755-762.

JUNIOR JACOBELIZ W. BASF no Mundo. 2008, 6 de novembro. Palestra no II Congresso Brasileiro de tomate industrial. Disponível em: http://www.congressotomate.com.br/

KISSMANN KG. 1998. Ajuvantes para caldas de produtos fitossanitários. In: GUEDES JVC; DORNELLES SB (eds). Tecnologia e segurança na aplicação de agrotóxico: novas tecnologias. Santa Maria: Departamento de Defesa Fitossanitária, Sociedade de Agronomia de Santa Maria. p. 39-51.

LEWIS MLI; MERA JR; MILLER SA. 2005, 4 de outubro. Evaluation of fungicides and bactericides for the control of foliar and fruit diseases of processing tomatoes. Disponível em: http://www.ag.ohio-state.edu/ vegnet/ library/res04/tomato.pdf/

LOPES CA; QUEZADO-DUVAL MA. 2005. Doenças bacterianas. In: LOPES CA; ÁVILA AC (ed) Doenças do tomateiro. Brasília: Embrapa-CNPH/Embrapa Hortaliças. p. 62-64.

LOPES CA; QUEZADO-SOARES AM. 2000. Doenças causadas por bactérias em tomate. In: ZAMBOLIM L; VALE FXR; COSTA H. (ed). Controle de doenças de plantas: hortaliças. Viçosa: UFV. p. 754-784.

LOPES CA; QUEZADO-SOARES AM. 1997. Doenças bacterianas das hortaliças-diagnose e controle. Brasília: EMBRAPA-CNPH. 70p.

MARCO GM; STALL RE. 1983. Control of bacterial spot of pepper initiated by strains of Xanthomonas campestris pv. vesicatoria that differ in sensitivity to copper. Plant Disease
67: 779-781.

MARINGONI AC; KUROZAWA C; BARBOSA V; SILVA NETO JC. 1986. Controle químico da mancha-bacteriana (Xanthomonas campestris pv. vesicatoria (Doidge) Dye) do tomateiro (Lycopersicon esculentum Mill.). Summa Phytopathologica 12: 92-101.

MELLO SCM; LOPES CA; TAKATSU A. 1997. Resistência de genótipos de tomateiro à mancha-bacteriana, em campo e em casa de vegetação. Fitopatologia Brasileira 22: 496-501.

NASCIMENTO AR; FERNANDES PM; ROCHA MR; SILVA EA. 2008. Fontes de fosfito e acibenzolar-s-metil no controle de doenças e produtividade do tomateiro. Bioscience Journal 24: 53-59.

NASCIMENTO ADR. 2006. Efeitos de fosfitos sobre a sanidade das plantas e produtividade na cultura do tomate. Goiânia: Universidade Federal de Goiás, UFG. 72 p (Tese mestrado).

OBRADOVIC A, JONES JB; MOMOL MT; OLSON SM; JACKSON LE; BALOGH B; GUVEN K; IRIARTE FB. 2005. Integration of biological control agents and systemic acquired resistance inducers against bacterial spot on tomato. Plant Disease 89: 712-716.

PARADELA AL; SCACHETTI AP; MUNHOZ R; BORIM JRN; CALAFIORI MH; GALLI MA. 2001. Eficiência de Bion (acibenzolarS-methyl) como indutor de resistência para o complexo bacteriano (Xanthomonas vesicatoria, Pseudomonas syringae pv. tomato e Clavibacter michiganense subsp., michiganense) e insetos vetores de fitoviroses na cultura do tomate (Lycopersicon esculentum L.). Revista Ecossistema 26: 17-22.

PITBLADO R. 2001. The development of pest management strategies for insects and plant diseases in processing tomatoes. Disponível em http://www.worldtomatocongress.com/ presentations/Poster/P19\%20Ron\%20 Pitblado.pdf $>$. Acessado em 20 outubro de 2008.

QUEZADO-DUVAL AM; LEITE JÚNIOR RP; LOPES CA; LIMA MF; CAMARGO LEA. 2005. Diversity of Xanthomonas spp. associated with bacterial spot of processing tomatoes in Brazil. Acta Horticulturae 695: 101-108.

QUEZADO-DUVAL AM. 2006. Manchabacterina do tomateiro e de Capsicum spp. Fitopatologia Brasileira. 31: S85-S85.

QUEZADO-SOARES AM; SILVA VL; GIORDANO LB; LOPES CA. 1998. Redução da produtividade de tomateiro para processamento industrial devido à manchabacteriana. In: CONGRESSO BRASILEIRO DE OLERICULTURA，38. Resumo... Petrolina: SOB. p. 266.

RIZZO AAN; FERREIRA RM; BRAZ LT. 2003. Ação de acibenzolar-S-methyl (BTH) isolado e em combinação com fungicidas no controle do cancro da haste em melão rendilhado. Disponível em: http://www. scielo.br/scielo.php?script $=$ sci arttex\&pid $=$ S0102-05362003000200024. Acessado em 27 janeiro de 2008.

RODRIGUES NETO J; SUGIMORI MH; MALAVOLTA JUNIOR VA. 1984. Raças de Xanthomonas campestris pv. vesicatoria 
(Doidge) dye, no estado de São Paulo. Arquivos do Instituto Biológico 51: 13-16.

ROMERO AM; KOUSIK CS; RITCHIE DF. 2001. Resistance to bacterial spot in bell pepper induced by acibenzolar-S-methyl. Plant Disease 85: 189-194.

SHEPHERD C; WILLIAMS R; SOEHNER S. 2004. Controlling fungal and bacterial diseases of tomatoes with TanosTM, a new fungicide from DuPont. In: $1^{\text {st }}$ International Symposium on Tomato Diseases and $19^{\text {th }}$ Annual Tomato Disease Workshop, 19. Florida. Resumos... Florida: University of Florida/IFAS Extension/ IHS. p. 48.

SILVA LHCP. 2002. Resistência sistêmica ativada pelo acibenzolar-S-metil contra doenças em tomateiro. Lavras: Universidade Federal de Lavras. 89 p (Dissertação mestrado).
SOUSA MAN. 2006. Avaliação do efeito do uso de fegatex ${ }^{\circledR}$ no controle de mancha-bacteriana em tomateiro para processamento industrial. Brasília: Faculdade da Terra de Brasília. 43p (Monografia bacharel em agronomia).

VILLAS BOAS GL; BRANCO MC. 2009. Manejo Integrado da Mosca Branca (Bemisia Tabaci Biótipo B) em Sistema de Produção Integrada de Tomate Indústria (PITI). Circular Técnica 70:16. 